\title{
Parvalbumin Interneurons of the Mouse Nucleus Accumbens are Required For Amphetamine-Induced Locomotor Sensitization and Conditioned Place Preference
}

\author{
Xiaoting Wang', David A Gallegos', Vladimir M Pogorelov², Justin K O’Hare', Nicole Calakos',3, \\ William C Wetsel ${ }^{1,2,4}$ and Anne E West*,I \\ 'Department of Neurobiology, Duke University Medical Center, Durham, NC, USA; ²Department of Psychiatry and Behavioral Sciences, Duke \\ University Medical Center, Durham, NC, USA; ${ }^{3}$ Department of Neurology, Duke University Medical Center, Durham, NC, USA; ${ }^{4}$ Department of \\ Cell Biology, Duke University Medical Center, Durham, NC, USA
}

\begin{abstract}
To determine the requirement for parvalbumin (PV) expressing GABAergic interneurons of the nucleus accumbens (NAc) in the behavioral adaptations induced by amphetamine $(A M P H)$, we blocked synaptic vesicle release from these neurons using Cre-inducible viral expression of the tetanus toxin light chain in male and female PV-Cre mice. Silencing PV+ interneurons of the NAc selectively inhibited the expression of locomotor sensitization following repeated injections of AMPH and blocked AMPH-induced conditioned place preference (CPP). AMPH induced significantly more expression of the activity-dependent gene Fos in both DI and D2 dopamine receptor-expressing medium spiny neurons (MSNs) of the NAc of PV+ interneuron silenced mice, suggesting a function for PV+ interneuron-mediated MSN inhibition in the expression of $\mathrm{AMPH}$-induced locomotor sensitization and $\mathrm{CPP}$. These data show a requirement for $\mathrm{PV}+$ interneurons of the NAc in behavioral responses to $\mathrm{AMPH}$, and they raise the possibility that modulation of PV+ interneuron function may alter the development or expression of psychostimulant-induced behavioral adaptations.

Neuropsychopharmacology (2018) 43, 953-963; doi:I0.1038/npp.2017.178; published online 27 September 2017
\end{abstract}

\section{INTRODUCTION}

Psychostimulant drugs of abuse induce plasticity in functional neural circuits within the brain's reward system, leading to the expression of addictive-like behaviors. Many studies have focused on the plasticity of medium spiny neurons (MSNs) in the nucleus accumbens (NAc) as a mechanism of these behavioral changes (Kauer and Malenka, 2007; Robison and Nestler, 2011). However, MSN firing is also modulated by multiple classes of local NAc interneurons (Kreitzer, 2009; Tepper et al, 2010). However, the roles of these neurons in the behavioral response to drugs of abuse are poorly understood. Parvalbumin (PV)-containing, fastspiking GABAergic interneurons (FSIs) comprise only $1-2 \%$ of all neurons in the NAc, yet they each make numerous, strong inhibitory synapses onto the somata and proximal dendrites of multiple nearby MSNs (Kita et al, 1990). Feedforward inhibition from $\mathrm{PV}+$ striatal interneurons filters cortical input to MSNs and controls MSN spike timing (Mallet et al, 2005). Thus PV+ interneurons are poised to have a major impact on the functional output of the NAc.

\footnotetext{
*Correspondence: Dr AE West, Department of Neurobiology, Duke University, 31 I Research Drive, DUMC Box 3209, Bryan Research 30ID, Durham, NC 277I0, USA, Tel: 919681 1909, Fax: 919681 443I,E-mail: west@neuro.duke.edu

Received 6 April 2017; revised 21 July 2017; accepted 9 August 2017; accepted article preview online 25 August 2017
}

Dopamine (DA) plays a key role in inducing circuit plasticities following psychostimulant exposure, and several lines of evidence suggest that PV+ interneurons are targets of regulation by DA-dependent signaling pathways. Upon amphetamine (AMPH) administration, FSIs fire robustly in vivo (Wiltschko et al, 2010), and in slice preparations these interneurons are directly excited by DA D1 receptor agonists (Bracci et al, 2002). Both AMPH and cocaine induce expression in NAc PV+ interneurons of the activityinducible transcription factor Fos as well as Ser421 phosphorylation of the methyl-DNA-binding protein $\mathrm{MeCP} 2$, raising the possibility that these neurons may undergo DA-dependent transcriptional adaptations (Deng et al, 2010). Indeed, repeated cocaine exposure increases the excitability of FSIs in the NAc (Winters et al, 2012), and long-term DA depletion alters the connectivity between PV+ interneurons and MSNs in the dorsal striatum in ways that can modulate striatal circuit properties (Gittis et al, 2011). However the functional requirement for NAc PV+ GABAergic interneurons in psychostimulant-induced addictive-like behaviors has remained unknown.

We hypothesized that the activity of PV+ interneurons in the NAc, via their regulation of MSN firing, are required for the development and/or expression of behavioral adaptations, including locomotor sensitization and conditioned place preference (CPP), that are induced by repeated exposure to AMPH. To test this hypothesis we used an 
intersectional genetic strategy to express tetanus toxin light chain (TeLC) selectively in PV+ interneurons of the NAc to determine the behavioral consequences of silencing output from these neurons within the local NAc circuit. Our data reveal a previously unknown requirement for $\mathrm{PV}+$ interneurons of the NAc in the expression of both locomotor sensitization and CPP induced by repeated AMPH exposure. The results from these studies increase our understanding of the cellular mechanisms that underlie psychostimulantinduced addictive behaviors.

\section{MATERIALS AND METHODS}

\section{Mice}

We performed all procedures under an approved protocol from the Duke University Institutional Animal Care and Use Committee. Homozygous female Pvalb-T2A-Cre (Pvalb-Cre) mice (Madisen et al, 2009) were purchased from The Jackson Laboratory (Bar Harbor, ME; B6.Cg-Pvalb ${ }^{\text {tm1.1(cre)Aibs }} /$ J, stock no. 012358) and crossed with male C57BL/6J mice (The Jackson Laboratory). Unless explicitly stated, all experiments used male or female mice that were heterozygous (HET) for the Pvalb-Cre allele. Eight independent cohorts of Pvalb-Cre HET mice were used. Two cohorts of male mice $(n=5,10$ / virus) and one of female mice ( $n=4$ /virus) were used for the sensitization experiments in Figure $2 \mathrm{a}-\mathrm{c}$ and Supplementary Figure $\mathrm{S} 1$ and the immunostaining in Figure $1 \mathrm{a}-\mathrm{d}$. A third cohort of male mice ( $n=2 /$ virus) was used for the electrophysiological experiments in Figure $1 \mathrm{e}-\mathrm{h}$ and a fourth ( $n=9$ /virus) was used for sensitization in Figure $2 \mathrm{e}$ and $\mathrm{f}$ and for the microdialysis in Figure 3. A second cohort of female mice ( $n=10 /$ virus/condition) was used for the CPP and sucrose preference experiments in Figure 5. These mice were combined with one additional female cohort ( $n=3 /$ virus) for the Fos analyses in Figure $4 \mathrm{a}$ and $\mathrm{b}$. One final cohort of male and female mice ( $n=5$ mice/virus) was used for the Fos mRNA in situ experiment in Figure $4 c$ and $d$.

\section{Antibodies}

We used goat anti-PV 1:1000 (PVG214; Swant, Marly, Switzerland), rabbit anti-VAMP2 1:1000 (104-202; Synaptic Systems, Goettingen, Germany), guinea pig anti-VGAT 1:500 (131-004 Synaptic Systems), rabbit anti-Fos 1:5000 (PC38; EMD Millipore, Billerica, MA); chicken anti-GFP (AB16901; EMD Millipore); secondary antibodies 1:500 conjugated to Cy2, Cy3 or Cy5 (Jackson ImmunoResearch, West Grove, PA).

\section{Stereotaxic Surgery}

Cre-inducible adeno-associated viral (AAV) plasmids containing GFP-tagged TeLC or GFP alone, each with the reading frame inverted in a flip-excision (FLEX) cassette (AAV-FLEX-TeLC and AAV-FLEX-GFP) were obtained from Dr Peer Wulff, Christian Albrechts University, Kiel, Germany (Murray et al, 2011). AAVs were generated by the University of Pennsylvania vector core facility or the Duke University viral vector core facility in serotype AAV2/5. Stereotaxic surgery was performed as in Deng et al (2010) to deliver viruses to the medial shell of the NAc using coordinates from Bregma of AP+1.6, ML1.5, DV -4.5, with the $\mathrm{T}$ bar set to $8^{\circ}$. We conducted behavioral experiments 3 weeks later.

\section{Electrophysiological TeLC Validation}

Animals were anesthetized via intraperitoneal injection of 2,2,2-tribromoethanol and 300 - $\mu$ m-thick brain slices were prepared using procedures for adult and aging mice (Ting et al, 2014). Data were acquired and digitized as previously described (Wan et al, 2011). Recording pipettes were pulled to 1.5-4 $\mathrm{M} \Omega$ resistance. During recordings, slices were continuously perfused with carbogenated standard ACSF (Wan et al, 2011) at $28-31^{\circ} \mathrm{C}$. A CsCl-based internal solution (Mathur et al, 2013) was used to detect inhibitory postsynaptic currents (iPSCs) of MSNs in whole-cell voltage clamp and action potentials in PV+ neurons in cell-attached mode. Recordings were carried out in the presence of NMDA and AMPA/kainate receptor blockers AP5 $(50 \mu \mathrm{M})$ and CNQX $(10 \mu \mathrm{M})$. To assess PV+ neuron-mediated GABAergic transmission onto MSNs, GFP- and mCherry-negative cells were patched in NAc where expression of PV-GFP and PV-mCherry were both prominent as determined by epifluorescence. While recording an $\mathrm{MSN}\left(V_{\text {hold }}=-70 \mathrm{mV}\right)$, a $\sim 0.5 \mathrm{~mm}$ radius spot surrounding the recorded cell was illuminated by a $473 \mathrm{~nm}$ LED (Thorlabs) at increasing light intensities to drive action potential firing in ChR2-expressing $\mathrm{PV}+$ neurons. Paired $3 \mathrm{~ms}$ light pulses were delivered $50 \mathrm{~ms}$ apart to obtain comparative measures of GABAergic release probability from PV+ neurons onto MSNs between GFP and TeLC groups (paired pulse ratio; PPR). PPR was calculated as $\log _{2}{ }_{2 \mathrm{PSC}_{2}}$ within-trial and averaged across trials. Series resistance was below $25 \mathrm{M} \Omega$ for whole-cell recordings and did not fluctuate by more than $2 \mathrm{M} \Omega$. To assess whether $473 \mathrm{~nm}$ light drove action potentials in $\mathrm{PV}+$ neurons expressing ChR2 and either TeLC $(n=1$ cell) or GFP ( $n=2$ cells), NAc neurons positive for both GFP and mCherry were recorded in cell-attached mode ( $V_{\text {hold }}$ $=0 \mathrm{mV}$ ). Single $3 \mathrm{~ms}$ light pulses were delivered at the same set of intensities used for iPSC recordings in MSNs in the same region of GFP and mCherry expression.

\section{Open Field Locomotor Activity and Locomotor Sensitization}

Each day mice were habituated to the open field (Accuscan Instruments, Columbus, $\mathrm{OH}$ ) for $1 \mathrm{~h}$ to establish baseline locomotor activity. Saline (as vehicle control) or $3 \mathrm{mg} / \mathrm{kg}$ AMPH (Sigma) was administered (i.p.) and mice were returned immediately to the open field for $1 \mathrm{~h}$. Locomotor activity was monitored as horizontal distance traveled $(\mathrm{cm})$. In sensitization protocol 1 (Figure $2 \mathrm{a}-\mathrm{c}$ and Supplementary Figure S1) mice were first stereotaxically injected in the NAc with the GFP or TeLC-GFP viruses 3 weeks before they were sensitized. On day 1 all mice received saline injections (i.p.) in the open field; on days 2, 3, 4, 5, and 6 all mice received $3 \mathrm{mg} / \mathrm{kg}$ AMPH (i.p.) in the open field; and on day 13 mice received a final challenge injection of $3 \mathrm{mg} / \mathrm{kg} A M P H . ~ I n$ protocol 2 (Figure $2 \mathrm{~d}-\mathrm{f}$ ), mice were sensitized before they were stereotaxically injected with the GFP and TeLC-GFP viruses. On days $1,2,3,4,5$, and 6 all mice received $3 \mathrm{mg} / \mathrm{kg}$ $\mathrm{AMPH}$ (i.p.) in the open field; 4 days later mice were 
a
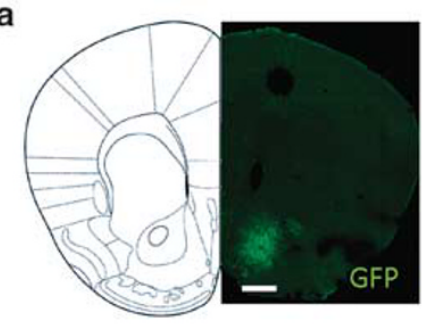

b

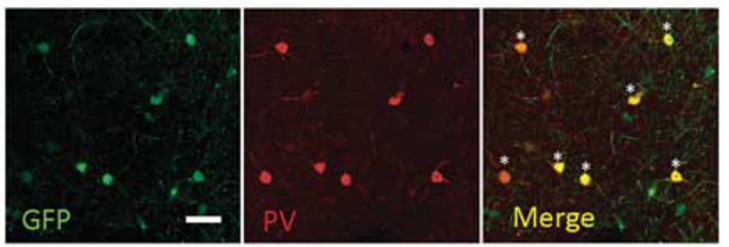

C
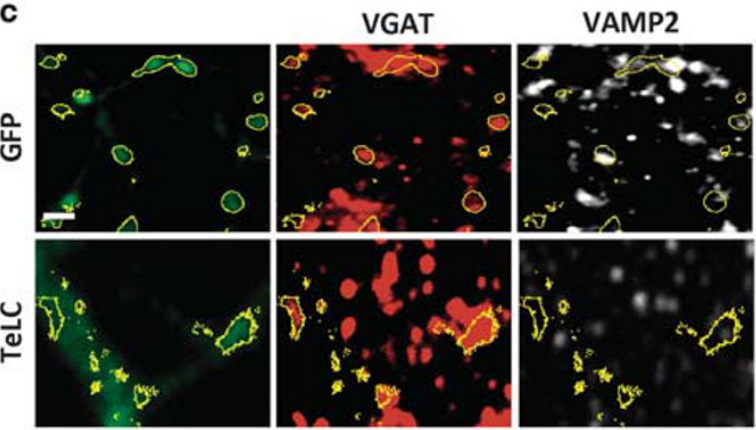

e
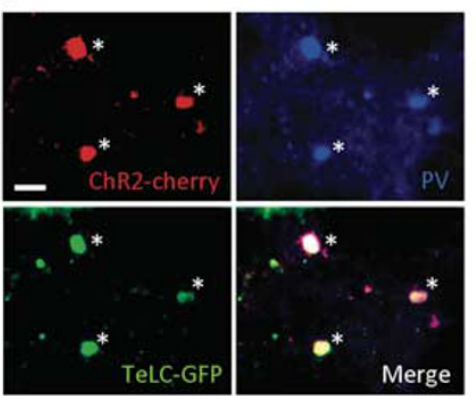

f
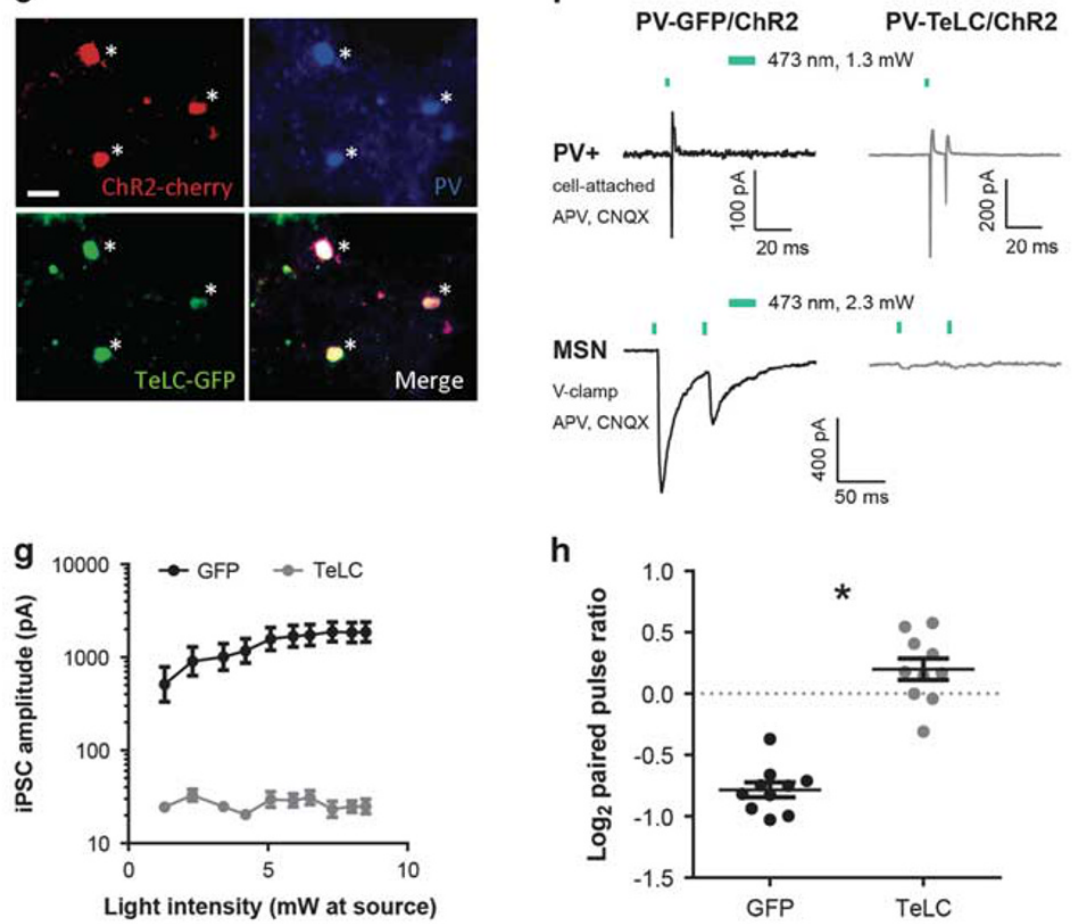

h

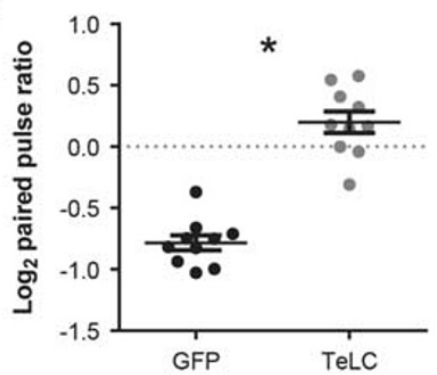

Figure I Cell-type specific AAV-mediated tetanus toxin light chain (TeLC) expression in PV+ GABAergic interneurons of the NAc in Pvalb-Cre mice. (a) Anatomical localization of stereotaxic viral injection in the mouse NAc. Coordinates AP: $1.18 \mathrm{~mm}$ from bregma, L: $1.18 \mathrm{~mm}$, adapted from Franklin and Paxinos (2007). Scale bar, $0.75 \mathrm{~mm}$. (b) Co-localization of AAV-mediated GFP expression (green) with PV immunoreactivity (red) in the NAc of Pvalb-Cre mice 3 weeks following stereotaxic viral infection. Colabeled cells are marked by an asterisk in the merge. Occasional GFP+/PV-cells (green in the merge view) are likely to have PV levels below our detection threshold as in Donato et al. (20I3). Scale bar, 30 um. (c) Identification of GFP+/VGAT+ synaptic terminals (yellow outlines) in the NAc of Pvalb-Cre mice infected with either TeLC-GFP (TeLC) or GFP as control for the assessment of VAMP2 expression. Scale bar, $2.5 \mu \mathrm{m}$. (d) Quantification of VAMP2 immunoreactivity in GFP+NGAT+ terminals in the NAc of mice infected as in (c). $n=4$ mice/virus; * $p<0.05$. (e) Credependent, AAV-mediated co-expression of ChR2-mCherry (red) and TeLC-GFP (green) in PV+ (blue) neurons of the NAc. Scale bar, I5 um. ( $\mathrm{f}$ ) Top: example traces showing light-evoked action potential firing in GFP/ChR2-expressing (left) and TeLC/ChR2-expressing (right) PV+ neurons in NAc. Action potentials were recorded in cell-attached mode. Bottom: Representative voltage clamp recordings showing MSN iPSCs evoked by paired-pulse photoactivation of nearby PV+ neurons expressing GFP/ChR2 (left) or TeLC/ChR2 (right). Green bar indicates light on. (g) Amplitudes of iPSCs evoked by the first light pulse in MSN recordings from PV-TeLC/ChR2 and PV-GFP/ChR2 mice. (h) Assessment of GABAergic release probability from PV+ neurons onto MSNs by comparing $\log _{2}$ paired-pulse ratios (PPR) between GFP and TeLC groups. $n=9$ MSNs from PV-GFP/ChR2 mice and IO MSNs from PV-TeLC/ChR2 mice, ${ }^{*} p<0.05$. 
a

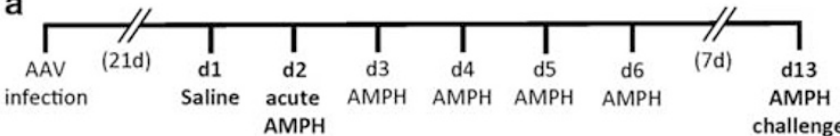

b
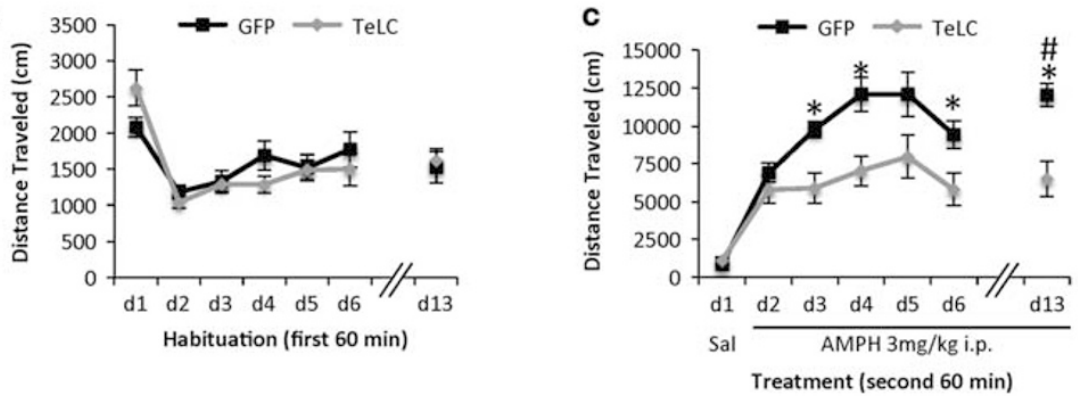

d
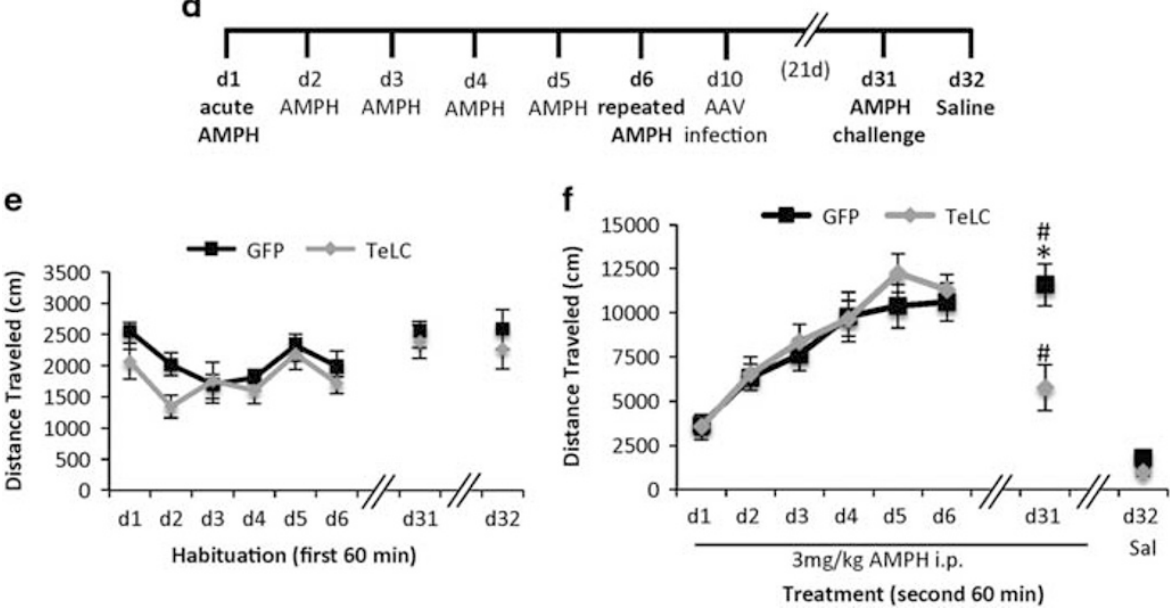

Figure 2 Silencing transmission from PV+ GABAergic interneurons of the NAc impairs the expression of behavioral sensitization to repeated AMPH administration in male mice. (a) Diagram of the locomotor sensitization procedure used for (b) and (c). (b) Distance traveled ( $\mathrm{cm}$ ) during the first 60 min of habituation to the open field for $\mathrm{dl}-6$ and d I3. (c) Distance traveled (cm) each day during the $60 \mathrm{~min}$ following injection (i.p.) of either saline (Sal only on $\mathrm{dI}$ ) or $3 \mathrm{mg} / \mathrm{kg}$ AMPH ( $\mathrm{d} 2-\mathrm{d} 6$ and $\mathrm{dl} 3$ ); $n=15$ male mice/virus; ${ }^{*} p<0.05$, GFP vs TeLC on a single day; ${ }^{*} p<0.05, \mathrm{dl} 3 \mathrm{AMPH}$ challenge vs $\mathrm{d} 2$ acute AMPH. (d) Diagram of locomotor sensitization procedure used for $(\mathrm{e})$ and $(\mathrm{f})$. (e) Distance traveled $(\mathrm{cm})$ during the first 60 min of habituation to the open field for $\mathrm{dl}-6, \mathrm{~d} 3 \mathrm{I}$, and d32. (f) Distance traveled $(\mathrm{cm})$ in the open field during the $60 \mathrm{~min}$ following injection of either $3 \mathrm{mg} / \mathrm{kg}$ AMPH i.p. (dI-d6, d3I) or saline (Sal, d32). AAVs expressing Cre-inducible GFP or TeLC were delivered by stereotaxic injection to the NAc of Pvalb-Cre mice on dI $0 . n=9$ male mice/virus. ${ }^{*} p<0.05$ GFP vs TeLC on d3I AMPH challenge; ${ }^{*} p<0.05 \mathrm{~d} 3$ I AMPH challenge vs day 32 saline (Sal).

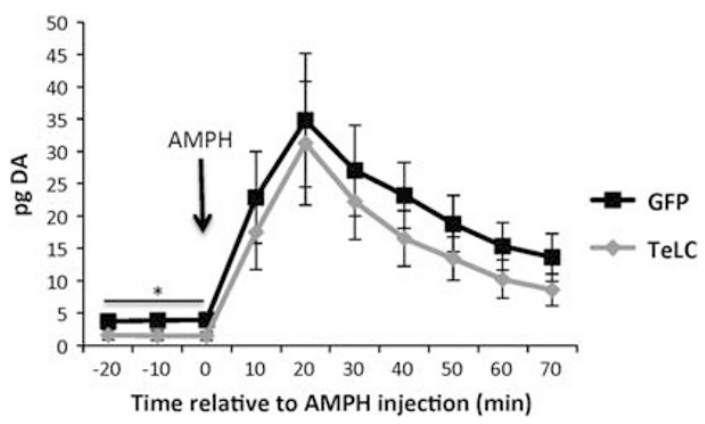

Figure 3 Silencing transmission from $\mathrm{PV}+\mathrm{GABAergic}$ interneurons of the NAc does not block AMPH-induced DA release in the NAc. DA measured by microdialysis from the NAc of mice expressing GFP or TeLC in GABAergic interneurons of the NAc that had been previously exposed to repeated $\mathrm{AMPH}$ injections (Figure $2 \mathrm{~d}-\mathrm{f}$ ). Basal expression was measured each mouse at $-20 \mathrm{~min},-10 \mathrm{~min}$, and $0 \mathrm{~min}$ prior to injection of $3 \mathrm{mg} / \mathrm{kg}$ AMPH (i.p.) in the home cage and samples were collected at 10 min intervals after injection for 70 min. $n=6$ GFP, $n=6$ TeLC mice; $* p<0.05$, GFP vs TeLC. stereotaxically injected with the GFP or TeLC-GFP viruses; 3 weeks later mice received a single challenge injection of $3 \mathrm{mg} / \mathrm{kg}$ AMPH in the open field; one day later all mice received saline (i.p.) in the open field as control.

\section{Microdialysis}

Microdialysis was performed as in Pogorelov et al (2005) on mice 6 weeks following AAV infection and 3 weeks following the sensitization shown in Figure $2 \mathrm{~d}$ and e. Animals were anesthetized with ketamine/xylazine i.p. and unilaterally implanted with guide cannulae targeted to the NAc at AP: $+1.2 \mathrm{~mm}$ from bregma, $\mathrm{L}:+3.0 \mathrm{~mm}, \mathrm{~V}:-2.8 \mathrm{~mm}$ (Franklin and Paxinos, 2007) at an angle of $14^{\circ}$ to avoid the previous microinjection track. Seven days after surgery we collected three baseline samples, delivered $3 \mathrm{mg} / \mathrm{kg}$ of AMPH (i.p.) and seven additional samples were collected. At the end of the experiment, we confirmed cannula placement within the virus-infected area. Two mice were excluded because of 
a

Saline

Acute AMPH

Repeated AMPH
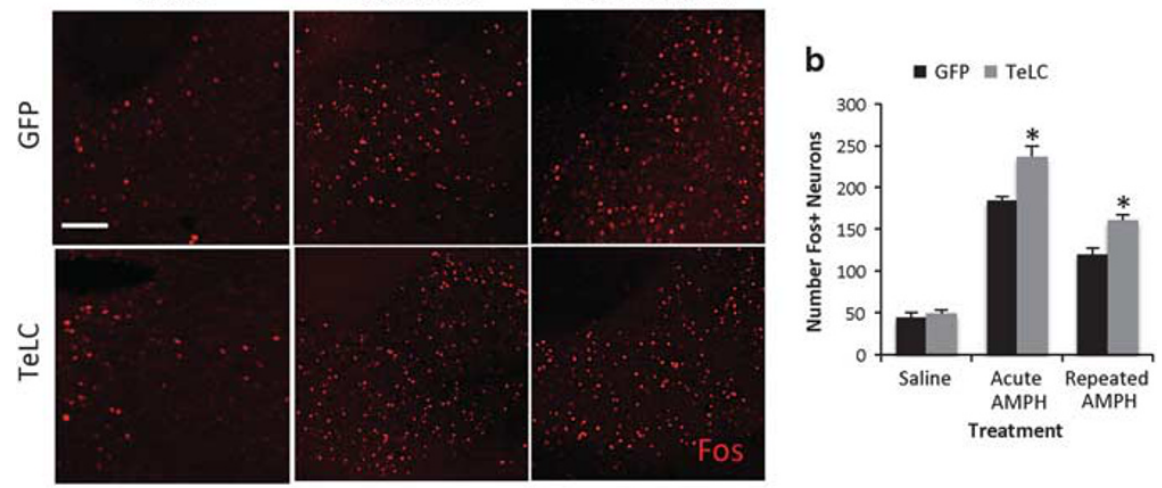

c
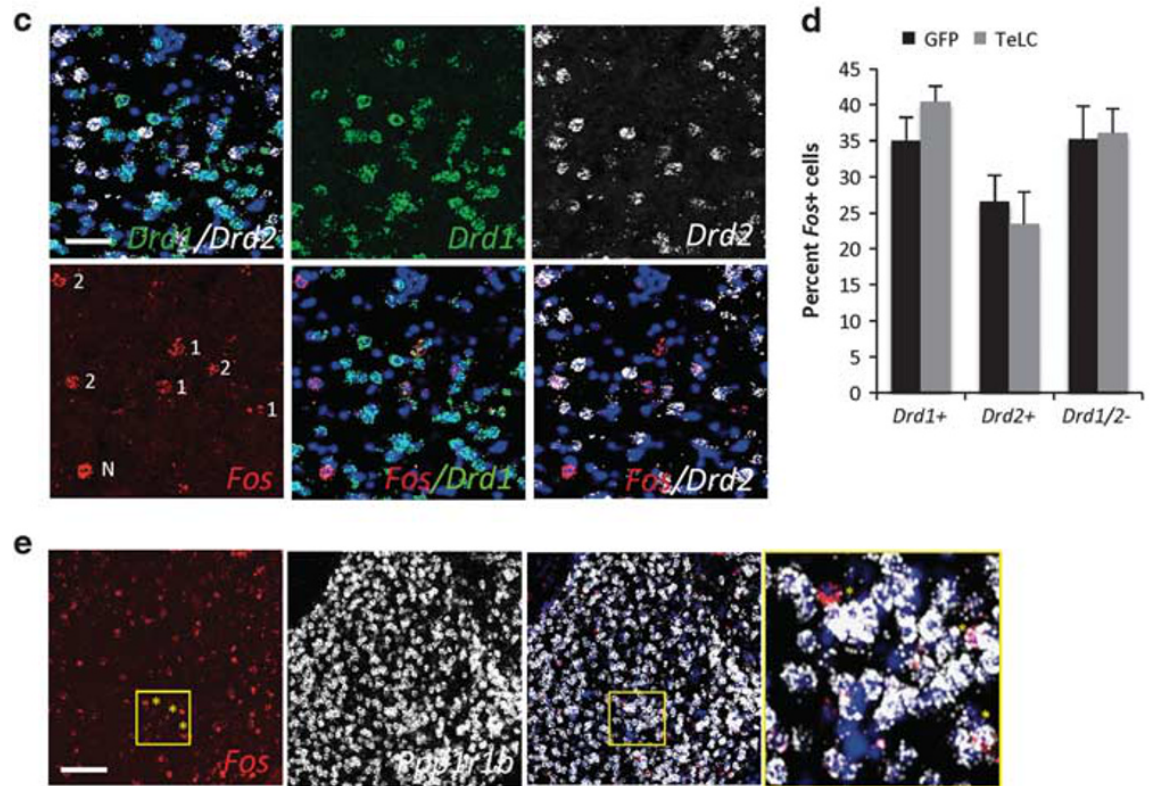

Figure 4 Enhanced AMPH-induced Fos expression in both DA DI- and D2-receptor expressing MSNs of the NAc in mice with PV+ GABAergic interneurons silenced. (a) Fos immunofluorescence in the NAc of mice expressing either GFP or TeLC in PV+ interneurons of the NAc $2 \mathrm{~h}$ following administration of saline, $3 \mathrm{mg} / \mathrm{kg}$ AMPH, or the challenge dose of $3 \mathrm{mg} / \mathrm{kg}$ AMPH i.p. following the protocol shown in Figure $2 \mathrm{~d}$. Scale bar, I00 $\mu \mathrm{m}$. (b) Quantification of the immunostaining from (a). $n=9$ mice/virus for $\mathrm{AMPH}$ and challenge groups, $n=3$ mice/virus for saline, * $p<0.05$ GFP vs TeLC within a treatment group. (c) Triple color fluorescence in situ hybridization for Fos, Drd I, and Drd2 in the NAc of mice I h following administration of the challenge dose of $3 \mathrm{mg} / \mathrm{kg}$ AMPH i.p. Nuclei (Nuc) are labeled in blue by Hoeschst. Colabeling of cells is indicated in the Fos panel as follows: I, colocalizes with Drd I; 2 , colocalizes with Drd2, N colocalizes with neither. Colocalization can be seen in the overlay panels to the right of Fos. Scale bar, 25 Hm. (d) Quantification of the percent of Fos+ cells in the NAc that overlap Drdl or Drd2 in mice expressing GFP or TeLC in PV+ GABAergic interneurons of the NAc. Percent was calculated as the number of Fos + cells colabeled for Drdl or Drd2 divided by the total number of Fos + cells in the same section. $n=5$ mice/virus. (e) Colocalization of Fos in the NAc after repeated AMPH with Ppp / rlb, which encodes the MSN marker Darpp-32. Three cells highlighted by asterisks in the yellow box are shown in the enlargement of the merge at right, in which one (upper left) does not colocalize with Ppp Irlb. Scale bar, 50 Hm.

probe misplacement. Samples were stored at $-80^{\circ} \mathrm{C}$ and analyzed with HPLC with electrochemical detection using the Alexys monoamine analyzer (Antec, Palm Bay, FL). The chromatograms were analyzed by the Clarity software package (DataApex, Prague, Czech Republic). A signal-tonoise ratio (SNR) of 3 was considered the limit of detection. Extracellular concentrations of DA, DOPAC, and HVA were expressed as pg/column.

\section{Immunofluorescence}

Two hours following open field administration of either saline or $3 \mathrm{mg} / \mathrm{kg}$ AMPH (i.p.) mice were transcardially perfused and processed for immunostaining as in Deng et al (2010). We performed immunofluorescence on either a Leica
DMI4000 wide-field microscope or a Leica SP8 confocal microscope. Immunofluorescence intensity was quantified using the Count Nuclei module in Metamorph (Molecular Devices, Sunnyvale, CA) for Fos and the Analyze Particles module in Fiji for VAMP2.

\section{In Situ Hybridization}

We performed RNAScope fluorescent in situ hybridization (FISH) for Fos, Drd1, and Drd2 mRNAs. One hour following the challenge dose of $3 \mathrm{mg} / \mathrm{kg}$ AMPH (i.p.) in the open field, brains were harvested and flash-frozen in an isopentane/dry ice bath (Thermo Fisher Scientific, Carlsbad, CA). Twenty micrometer coronal sections were cut on a cryostat and the slices were mounted on Super Frost Plus slides 
(Fisher Scientific). We used the following probes (Advanced Cell Diagnostics, Newark, CA): Mm Fos-C3 probe (Cat\# 316921-C3; GenBank accession number NM_010234.2; target region, 407-1427); $\mathrm{Mm}$ Drd1-C1 probe (Cat \# 406491-C1; GenBank accession number NM_010076.3; target region, 444-1358), $\mathrm{Mm}$ Drd2-C2 probe (Cat\# 406501-C2; GenBank accession number NM_010077.2; target region, 69-1175); and $\mathrm{Mm} \mathrm{Ppp1r1b-C2} \mathrm{probe} \mathrm{(Cat \#}$ 405901; GenBank accession number NM_144828.1; target region, 590-1674). We incubated sections for 30s with DAPI to label nuclei of all cells. Two sections were imaged for each brain and three nonoverlapping fields were captured to tile the full medial extent of the NAc. Z-stack images were taken at $\times 20$ on a Leica SP8 confocal microscope and analyzed in FIJI/ImageJ. For each Fos-positive cell we determined by focusing through the z-stack whether it was co-localized with $\operatorname{Drd1}$, Drd2, both, or neither and the numbers of each category were summed across the three fields for each section then reported as a percent of total Fos+ cells. In separate experiments we did the same for each Fos + cell asking it was co-localized with Ppp1r1b.

\section{Conditioned Place Preference}

CPP testing was conducted in a three-chambered apparatus with equal-sized chambers $(16.8 \times 12.7 \times 12.7 \mathrm{~cm})$ different in color (black $v s$ white) and floor texture (grid or bar) joined by a smaller chamber $(7.2 \times 12.7 \times 12.7 \mathrm{~cm})$, with manually operated doors and equipped with infrared diodes (MedAssociates, St Albans, VT). CPP was as in Deng et al (2010) with the following modifications. All mice received stereotaxic NAc injections with GFP or TeLC-GFP viruses 3 weeks prior to testing. On day 1, we acclimated mice to the CPP apparatus by placing them into the center chamber and allowing them free access to the entire apparatus for $30 \mathrm{~min}$. Conditioning began on day 2 and consisted of three two-day pairing cycles. The chamber paired with AMPH was randomly assigned regardless of initial chamber preference on day 1 . On the first day (day 2) of conditioning and every other day afterwards (days 4 and 6), we administered $2 \mathrm{mg} /$ $\mathrm{kg}$ AMPH (i.p.) and confined the mice to the drug-paired chamber for $30 \mathrm{~min}$. On alternate days (days 3, 5, and 7), we administered saline (i.p.) and confined mice to opposite chamber. Control mice were injected with saline on all paring days (days 2-7). The designated 'drug' paired chamber was the chamber used on day 2. Forty-eight hours after the final day of conditioning (day 9), mice were placed into the center chamber, allowed free access to the entire apparatus for $30 \mathrm{~min}$, and the time spent in each chamber was recorded. For data analyses, we calculated a CPP Difference Score as the amount of time in seconds the mouse spent in the designated 'drug'-paired chamber on the challenge day minus the amount of time in seconds the mouse spent in the same chamber on the acclimation day. One week later, all mice that received only saline (control groups) were subsequently tested for sucrose preference as described below.

\section{Sucrose Preference}

Sucrose preference was assessed using a two-bottle choice test. Mice were housed individually in the home cage and were given two bottles of water for at least 8 days until stable and non-biased water drinking from both bottles was achieved. Liquid intake was measured for $24 \mathrm{~h}$ by recording the bottle weights. Subsequently, water in one bottle was paired with another bottle containing sucrose at concentrations of $0.5,0.75$, or $1 \%$, each for 3 consecutive days. After the series of sucrose solutions, animals were re-trained for water drinking from both bottles. A second choice test was repeated by pairing water with $0.3 \mu \mathrm{M}$ quinine to test gustatory responses to quinine. Preference for sucrose (positive values) or avoidance to quinine (negative values) was calculated by subtracting the volume of water in bottle A consumed from the volume of sucrose or quinine solution in bottle B consumed on the same day, and then dividing that quantity by the total liquid consumption on each testing day.

\section{Statistics}

Data are presented as means \pm SEM and analyzed using SPSS (IBM SPSS Statistics, Armonk, NY). Comparisons between two independent samples were analyzed with a Student's unpaired $t$-test. Open field, microdialysis, sucrose/quinine preference, and electrophysiology data were analyzed by twoway repeated measures ANOVA (rmANOVA) with treatment or time (days) as a within-subject and virus as the between-subject factors followed by Bonferroni post hoc tests where applicable. Fos protein induction data were analyzed by two-way ANOVA with virus and treatment as the between-subjects factors and CPP data were analyzed by two-way ANOVA with drug pairing and virus as the between-subjects factors. A $p<0.05$ was considered significant.

\section{RESULTS}

Selective Disruption of Synaptic Transmission from PV+ GABAergic Interneurons of the NAc Impairs Behavioral Sensitization to Repeated AMPH Exposure

To determine the role played by $\mathrm{PV}+\mathrm{GABAergic}$ interneurons of the NAc in behavioral adaptations induced by AMPH, we silenced synaptic transmission from these neurons via cell-type specific viral expression of the TeLC. We bilaterally stereotaxically injected Cre-inducible adenoassociated viruses (AAVs) expressing GFP-tagged TeLC or GFP alone as control (Murray et al, 2011) into the medial shell region of the NAc of mice that were heterozygous for expression of the Cre recombinase from a transgene knocked into the Pvalb locus (Madisen et al, 2009) (Figure 1a). For both viruses we observed GFP expression in PV+ cells of the NAc in a pattern consistent with the known enrichment of $\mathrm{PV}+$ neurons in the rostral shell (Figure $1 \mathrm{a}$ and $\mathrm{b}$; Todtenkopf et al, 2004). Quantification of overlap showed viral expression in $60.9 \pm 5.9 \%$ of identified $\mathrm{PV}+$ neurons within the NAc ( $n=5$ mice/virus).

TeLC cleaves the synaptic vesicle protein VAMP2 to block neurotransmitter release (Murray et al, 2011; Schiavo et al, 1992; Yamamoto et al, 2003). We found that VGAT+ terminals of neurons in the NAc expressing TeLC-GFP showed a $\sim 50 \%$ reduction in VAMP2 immunoreactivity compared with control GFP-expressing VGAT+ terminals (Figure $1 \mathrm{c}$ and $\mathrm{d}, n=4 \mathrm{mice} / \mathrm{virus,} p=0.05$ ). The residual 
VAMP2 immunoreactivity may reflect low-affinity antibody recognition of the cleavage products (Yamamoto et al, 2003). To confirm that TeLC blocked neurotransmission from PV+ neurons, we stereotaxically co-injected a Cre-inducible AAVexpressing ChR2-mCherry with either TeLC-GFP or GFP into the NAc (Figure 1e). We then prepared acute brain slices and photoactivated $\mathrm{PV}+$ neurons while recording postsynaptic responses in MSNs. Four hundred and seventy-three nanometer light drove action potentials in $\mathrm{PV}+$ neurons in slices from both PV-GFP/ChR2 and PV-TeLC/ChR2 mice (Figure 1f, top). MSN iPSCs were recorded after paired-pulse photoactivation of nearby $\mathrm{PV}+$ neurons co-expressing GFP/ ChR2 or TeLC/ChR2 (Figure 1f, bottom). Light-evoked iPSCs were orders of magnitude smaller in MSNs from PVTeLC/ChR2-expressing mice relative to those from PV-GFP/ ChR2 mice (Figure 1g, rmANOVA group effect $\mathrm{F}_{1,17}=11.41$, $p=0.004, n=9 \mathrm{MSN}$ from $2 \mathrm{PV}-\mathrm{GFP} / \mathrm{ChR} 2$ mice and 10 MSNs from 2 PV-TeLC/ChR2 mice) and this effect increased with light intensity $\left(\mathrm{F}={ }_{9,153}=8.67, p<0.0001\right)$. PPRs were also consistent with a lower release probability in PV-TeLC/ ChR2 mice relative PV-GFP/ChR2 (Figure 1h, $p<0.0001$ ). These results show that TeLC significantly and dramatically reduces neurotransmission from $\mathrm{PV}+$ neurons onto MSNs in the NAc.

To determine whether PV+ GABAergic neurons of the NAc are required for locomotor sensitization to $\mathrm{AMPH}$, we first subjected two independent cohorts of male mice expressing TeLC or GFP in PV+ neurons of the NAc to daily saline or AMPH injections in the open field (Figure 2a). Because the magnitude of locomotor sensitization to psychostimulants can differ by sex (Milesi-Halle et al, 2007; Peris et al, 1991), we separately tested a cohort of female TeLC or GFP-expressing mice in the same procedure. We observed no obvious deficits in male or female mice expressing either TeLC or GFP in PV-positive interneurons of the NAc, and for both sexes rmANOVA showed statistically indistinguishable baseline locomotor activity between the viral groups during daily habituation to the open field (Figure $2 \mathrm{~b}$, males, there was a significant effect of days $\mathrm{F}_{6,156}=18.96, \quad p<0.001$, but no effect of virus $\mathrm{F}_{1,26}=0.003, p=0.96$; Supplementary Figure S1A, females).

We confirmed that both GFP and TeLC-expressing mice displayed a significant increase in locomotor activity following treatment in the open field with acute $\mathrm{AMPH}$ compared with saline treatment; however, the TeLC mice selectively failed to show sensitization upon repeated AMPH treatment (Figure 2c). For male mice rmANOVA showed a significant main effect of days $\mathrm{F}_{6,162}=32.54, p<0.001$, a significant main effect of virus $\mathrm{F}_{1,27}=12.19, p=0.002$, and a significant days $\times$ virus interaction $\mathrm{F}_{6,162}=3.51, p=0.003$. Both GFP and TeLC-expressing mice showed locomotor stimulation induced by AMPH compared with saline (for GFP $\mathrm{d} 2$ vs $\mathrm{d} 1 p<0.001$, for TeLC $\mathrm{d} 2$ vs $\mathrm{d} 1 \quad p<0.001)$. However, when we repeated AMPH exposure in the open field and then tested for locomotor sensitization with a challenge dose of AMPH, the further increase in locomotor activity that indicates sensitization was present only in the GFP mice and was absent from the TeLC mice (Figure 2c). Specifically, whereas the mice expressing GFP displayed significantly increased locomotor activity following repeated AMPH treatment upon challenge compared with their response to acute AMPH injection $(p=0.001$, GFP on $\mathrm{d} 13$ vs $\mathrm{d} 2$ ), the TeLC-expressing mice showed no increase in locomotor activity over this same period $(p=1.0$, TeLC on $\mathrm{d} 13$ vs $\mathrm{d} 2$ ). Furthermore, on the challenge day, mice expressing TeLC in PV+ neurons of the NAc showed significantly lower locomotor activity compared with the GFP expressing group $(p<0.001$ d13 GFP vs TeLC; Figure 2c). Female mice with TeLC-based PV+ neuron silencing showed a similar trend toward impaired sensitization (Supplementary Figure S1B). Thus these data show that expressing TeLC in PV+ interneurons of the NAc selectively inhibits the locomotor sensitization induced by repeated AMPH.

To demonstrate that the ability of the TeLC virus to inhibit locomotor sensitization required Cre-inducible expression of TeLC in PV+ neurons, we delivered the GFP or TeLC AAVs into a cohort of male inbred C57BL/6 mice (no Cre expression) as a negative control. In this experiment, repeated injection of AMPH produced locomotor sensitization that was indistinguishable between the viral groups (Supplementary Figure S2).

Acquisition of behavioral sensitization takes place when a mouse experiences daily exposure to AMPH; the expression of sensitization is assessed by a locomotor response to an AMPH challenge after some time has passed. To determine when neurotransmission from $\mathrm{PV}+\mathrm{GABAergic}$ neurons of the NAc is required for expression of behavioral sensitization, we first exposed a cohort of male Pvalb-Cre mice to repeated $A M P H$ injections in the open field and then tested the consequences of silencing PV + neurons in the NAc only after sensitization had been established (Figure 2d). As expected, rmANOVA revealed that there was no effect of the virus on locomotor activity during habituation to the open field (Figure 2e, significant main effect of days $\mathrm{F}_{7,98}=4.6$, $p<0.001$ but no effect of viral group $\mathrm{F}_{1,14}=3.97, p=0.07$ ). Prior to viral infection both groups developed indistinguishable locomotor sensitization (Figure $2 \mathrm{f}$, significant effect of days $\mathrm{F}_{5,80}=50.75, p<0.001$, but no effect of viral group $\mathrm{F}_{1}$, $\left.{ }_{14}=0.22, p=0.65\right)$. However virally inducing expression of TeLC but not GFP in PV+ neurons after sensitization had been established selectively eliminated the expression of the sensitized locomotor response at challenge, without fully blocking the locomotor stimulation induced by AMPH (Figure 2f). Comparing the locomotor response at the AMPH challenge on $d 31$ to the saline test on $d 32$, rmANOVA revealed a significant main effect of treatment $\left(\mathrm{F}_{1,14}=70.19, p<0.001\right)$, a significant effect of the virus $\left(\mathrm{F}_{1,14}=13.43, p=0.003\right)$ and a significant virus $\times$ days interaction $\left(\mathrm{F}_{1,14}=8.3, p=0.012\right)$. Post hoc Bonferroni tests showed significantly reduced locomotor activity on the challenge day 31 when TeLC mice were compared with the GFP mice $(p=0.005)$. However both the GFP mice and the TeLC mice still showed significantly greater locomotor activity after injection of AMPH on $\mathrm{d} 31$ compared with that to the saline injection on $\mathrm{d} 32$ (for GFP $\mathrm{p}<0.001$, for TeLC $p=0.002)$. Thus, inhibiting neurotransmission from $\mathrm{PV}+$ GABAergic neurons of the NAc selectively impairs expression only of the sensitized component of the locomotor response to $\mathrm{AMPH}$. 
AMPH-Induced DA Release into the NAc is not Blocked by Silencing PV+ GABAergic Interneurons of the NAc

Locomotor sensitization is associated with enhanced DA release in the NAc (Pierce and Kalivas, 1997). Because the TeLC-expressing mice failed to exhibit locomotor sensitization, we wondered whether local inhibition of PV+ neurons within the NAc changed local extracellular DA release. We performed microdialysis for DA in the NAc of the cohort of mice shown in Figure $2 \mathrm{~d}-\mathrm{f}$ that had previously been sensitized to repeated AMPH injections (Figure 3). At baseline in the home-cage $(-20$ to $0 \mathrm{~min})$, DA levels were slightly but significantly lower in the TeLC mice compared with the GFP controls (rmANOVA effect of virus: $\mathrm{F}_{1,10}=8.42, \quad p<0.016$, no significant effects of time or interaction). More importantly for this study, however, a single injection of $3 \mathrm{mg} / \mathrm{kg}$ AMPH elevated DA levels in both groups over time (Figure 3; rmANOVA effect of time: $\mathrm{F}_{6,60}=$ $9.84, p<0.001)$ and this rise in DA was not different between mice expressing the GFP or TeLC viruses (effect of virus $\mathrm{F}_{1,10}=0.54, p=0.48$, and no significant time $\times$ virus interaction). Furthermore, there were no main effects or significant interactions for DA metabolites ( $p$-values $>0.5$; Supplementary Figure S3). Thus these data indicate that the reduced locomotor sensitization to $\mathrm{AMPH}$ in the mice with silenced $\mathrm{PV}+$ interneurons in the NAc is not due to an impairment of AMPH-induced DA release in the NAc.

\section{Inhibition of PV+ Neurons of the NAc Leads to Hyperactivation of both D1- and D2R+ MSNs}

DA released into the NAc acts postsynaptically on neurons to modulate their firing properties. MSNs are the major output cells of the NAc, and decreases in their firing rates due to reduced intrinsic excitability are thought to mediate behavioral sensitization to psychostimulants (Dong et al, 2006; Hu et al, 2004; Kourrich et al, 2013; Kourrich and Thomas, 2009). To determine whether the silencing of PV+ neurons in the NAc alters MSN firing following repeated $\mathrm{AMPH}$, we used induction of the immediate early gene product Fos as a marker of neurons that were activated in vivo by AMPH (Graybiel et al, 1990). Similar to previous studies we found that Fos was induced in the NAc by both acute and repeated AMPH administration (Figure 4a). However, we also observed that AMPH administration induced significantly more cells to express Fos when TeLC was expressed in PV+ GABAergic interneurons of the NAc compared with GFP-expressing mice (Figure $4 \mathrm{a}$ and $\mathrm{b}$ ). Two-way ANOVA showed a significant main effect of treatment $\mathrm{F}_{2,40}=217.2, p<0.001$, a significant main effect of virus $\mathrm{F}_{1,40}=28.62, p<0.001$, and a significant virus $\times$ treatment interaction $\mathrm{F}_{2,40}=4.89, p=0.13$. Specifically, there was significantly more Fos+ induced in the TeLCexpressing mice compared with the GFP-expressing mice after either acute $(p<0.001, n=9 \mathrm{GFP}, 7$ TeLC mice) or repeated AMPH $(p<0.001, n=9$ mice/virus $)$. Colocalization analysis revealed that most Fos+ cells did not co-express the GFP or TeLC viruses (Supplementary Figure S4), which label the $\mathrm{PV}+$ neuron population, suggesting that these were likely to be MSNs, which are the most populous neurons in the NAc.
MSNs expressing the DA D1-receptors (D1R) vs the D2type receptors (D2R) have a number of distinct cellular properties including their synaptic strengths, firing rates, and projection targets (Gerfen and Surmeier, 2011; Kreitzer, 2009). PV+ GABAergic interneurons are known to synapse onto both classes of MSNs, and DA depletion has been shown to enhance synaptic coupling of PV+ interneurons to D2R MSNs in dorsal striatum, suggesting a mechanism via DA-dependent $\mathrm{PV}+$ neuron plasticity to alter the balance between the direct and indirect MSN pathways (Gittis et al, 2011). To determine whether silencing PV+ GABAergic neurons of the NAc alters the balance in activation of D1Ror D2R-expressing MSNs, we again used Fos as an indicator of in vivo neuronal activity; however, now we used multicolor FISH protocol to colocalize AMPH-induced Fos mRNA with Drd1 and Drd2 expressing MSNs in the NAc. Consistent with our observations for Fos protein, following the challenge dose of AMPH in our sensitization procedure, we found substantial numbers of NAc neurons expressing Fos mRNA in both the GFP- and TeLC-expressing mice. As we and others have reported previously (Badiani et al, 1999; Deng et al, 2010), Fos was induced upon repeated open field AMPH exposure in both Drd1 and Drd2 expressing MSNs (Figure 4c). Both the GFP and the TeLC-expressing mice showed a predominance of Fos expression in the Drd1 population of MSNs (Figure 4d). However there was no significant difference comparing mice that had GFP vs TeLC expressed in the PV+ neurons of the NAc in the relative percentage of Fos expressed in Drd1+ $(p=0.18$, GFP vs TeLC) or Drd2+ ( $p=0.61$, GFP $v s$ TeLC) MSNs (Figure 4d). Somewhat surprisingly we also found that a substantial percentage of Fos+ neurons in the NAc expressed neither Drd1 nor Drd2, although $88.2 \pm 3.6 \% \quad(n=3$ mice from Figure 4d) of the Fos+ neurons co-labeled for Ppp1r1b, which encodes the MSN marker protein Darpp-32 (Figure 4e). Although to our knowledge the percentage of MSNs in the NAc that lack Drd1 or Drd2 has not been rigorously reported, a recent study using BAC transgenic mice identified a population of Adora2a+ MSNs in the ventral and medial shell of the NAc that appear to lack Drd1 and Drd2 (Gangarossa et al, 2013). Regardless of the identity of our Drd1/2-lacking MSNs, again the percentage of Fos induced in this population also did not differ between the GFP and TeLC-expressing mice ( $p=0.88$, GFP $v s$ TeLC). Thus these findings suggest that silencing of synaptic transmission from $\mathrm{PV}+$ interneurons globally disinhibits all populations of MSNs in the NAc, consistent with the reported broad synaptic connectivity of single PV+ interneurons to multiple striatal projection neurons.

\section{AMPH-Induced CPP is Impaired by Silencing PV- Positive GABAergic Interneurons of the NAc}

In addition to their locomotor stimulatory effects, psychostimulant drugs of abuse have rewarding properties that can be measured by their ability to induce CPP (Haggkvist et al, 2009; Mathews et al, 2010). To determine whether neurotransmission from PV+ GABAergic interneurons of the NAc is required for this form of conditioning, we stereotaxically injected a cohort of female Pvalb-Cre mice with the Creinducible GFP or TeLC viruses in the NAc, and 3 weeks later mice were tested in AMPH-induced CPP (Figure 5a). 
a
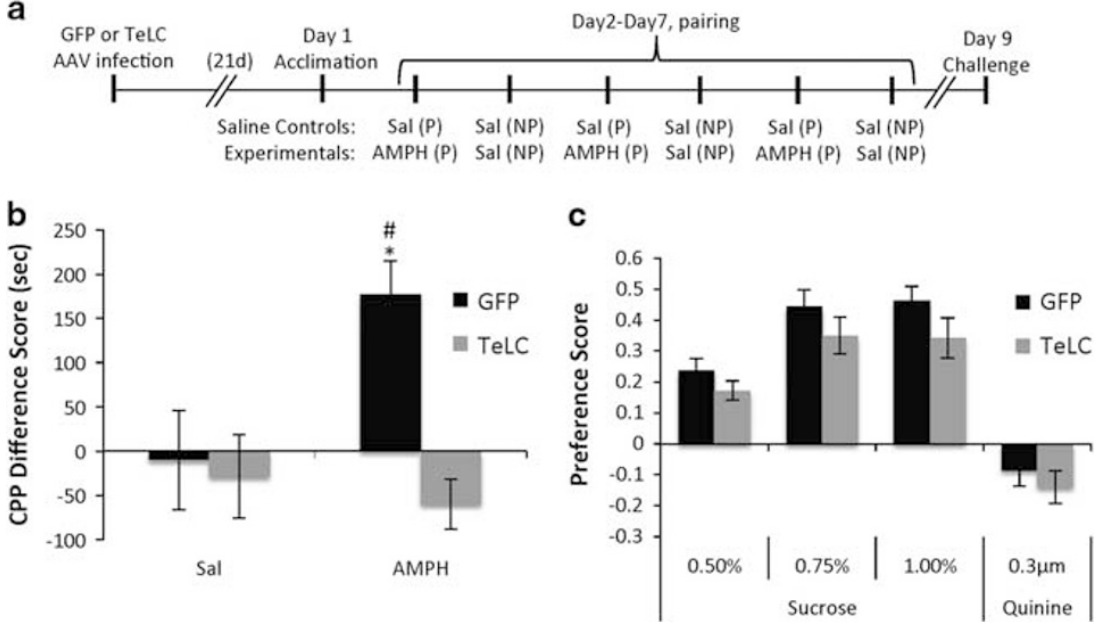

Figure 5 Silencing transmission from PV+ GABAergic interneurons of the NAc impairs AMPH-induced conditioned place preference but not sucrose reward. (a) Diagram showing the CPP procedure used in this study. Sal, saline; AMPH, 2 mg/kg AMPH (i.p.). P designates delivery of Sal or AMPH in the assigned 'drug-paired' chamber, and NP designates delivery of Sal or AMPH in the opposite, 'non-paired' chamber. (b) Difference in time spent in the assigned 'drug-paired' chamber (sec) after repeated pairing with either saline or AMPH (2 mg/ $/ \mathrm{gg}$, i.p.) compared with time spent in the same chamber during acclimation. $n=10$ mice/virus (GFP, TeLC) and 10 mice/treatment-condition (Sal, AMPH). ${ }^{*} p<0.05$, GFP mice treated with AMPH vs Sal; ${ }^{\#} p<0.05$, AMPH treated mice, expressing GFP vs TeLC. (c) Two bottle choice test showing preference for drinking sucrose or quinine at the concentrations noted compared with water. $n=10$ mice/virus.

Two-way ANOVA for the difference in time spent in the designated drug-paired chamber on the test day compared with the habituation day revealed a significant virus $\times$ drug interaction $\left(\mathrm{F}_{1,31}=5.8, p=0.02\right.$; Figure $\left.5 \mathrm{~b}\right)$. Mice infected with GFP developed a significant preference for the AMPH$v s$ the saline-paired chamber $(p=0.004)$. By contrast, mice expressing TeLC showed no difference in their preference for the AMPH-paired compared to the saline-paired chamber $(p=0.65)$.

A generalized hedonic deficit may contribute to the deficient expression of the conditioned AMPH reward in TeLC mice. To exclude this possibility, we took the GFP and TeLC-expressing mice that had been exposed only to saline in the CPP procedure and subsequently tested them for sucrose preference in a two-bottle choice test. A two-way rmANOVA revealed that both TeLC and GFP-expressing mice showed a concentration-dependent preference for sucrose over water (main effect of sucrose concentration: $\left.\mathrm{F}_{1,15}=18.1, p<0.001\right)$ and as a control both the GFP and TeLC groups showed an aversion to quinine (Figure $5 \mathrm{c}$ ). However, no significant differences in sucrose preferences were noted between the viral groups (main effect of virus: $\mathrm{F}_{1,15}=2.76, p=0.12$ ) or in the concentration $\times$ virus interaction $\left(F_{1,15}=0.26, p=0.76\right)$. Taken together these data show synaptic transmission from $\mathrm{PV}+$ neurons of the NAc is required for $\mathrm{AMPH}$-induced $\mathrm{CPP}$, and we discuss potential mechanisms below.

\section{DISCUSSION}

Although the NAc is well-known to play an important role in the development and expression of addictive-like behaviors induced by repeated exposure to psychostimulant drugs of abuse, the contribution of local NAc interneurons to these behavioral responses has remained poorly understood. Acute AMPH administration robustly induces the firing of striatal PV+ GABAergic interneurons (Wiltschko et al, 2010), and repeated exposure to psychostimulants drives both molecular (Deng et al, 2010, 2014) and electrophysiological adaptations (Winters et al, 2012) in these neurons. To determine if PV+ interneurons play a functionally important role in the development of addictive-like behaviors induced by repeated AMPH administration, we used stereotactic delivery of a TeLC-expressing AAV to silence transmission from these neurons in adult male and female mice. We found that silencing transmission from $\mathrm{PV}+$ interneurons of the NAc selectively blocked the expression of AMPH-induced locomotor sensitization and CPP without inhibiting either basal locomotor activity or the psychomotor activation induced by acute AMPH administration. These data provide evidence that PV+ GABAergic interneurons of the NAc are required for behavioral adaptations induced by psychostimulant drugs of abuse.

\section{PV+ Interneuron Regulation of MSNs in Locomotor Sensitization and CPP}

Changes in MSN firing underlie the expression of locomotor sensitization; however, multiple cellular mechanisms contribute to psychostimulant-induced changes in NAc output (Wolf, 2010). Persistent decreases in intrinsic excitability of MSNs have been observed following repeated exposure to both cocaine and AMPH, and experimentally decreasing MSN intrinsic excitability is sufficient to induce a sensitizedlike locomotor state (Dong et al, 2006; Kourrich et al, 2013; Kourrich and Thomas, 2009). Locomotor sensitization is also associated with increased release of DA from VTA terminals in the NAc, which then acts on MSNs to alter their excitability (Pierce and Kalivas, 1997). Our data now add a role for local circuit interneurons in this network. PV+ GABAergic interneurons make multiple, strong inhibitory synapses onto the somata and proximal dendrites of both D1R- and D2R-expressing MSNs (Gittis et al, 2011, 2010). Despite their small numbers in the striatum $(\sim 1-5 \%$ of all cells) (Kawaguchi et al, 1995; Tepper and Bolam, 2004), 
$\mathrm{PV}+$ interneurons account for up to $15-30 \%$ of all GABAergic synapses onto MSNs (Guzman et al, 2003). Activation of PV+ interneurons leads to profound feedforward inhibition in striatal circuits, such that even a single action potential fired in a PV+ interneuron can significantly decrease firing of its target MSNs (Koos and Tepper, 1999). Consistent with a physiological function for this $\mathrm{PV}+$ interneuron-mediated MSN inhibition in locomotor sensitization to repeated AMPH exposure, we found that silencing transmission from $\mathrm{PV}+$ interneurons resulted in increased expression of the cellular activity marker Fos in both D1Rand D2R-expressing MSNs of the NAc (Figure 4). This effect appears to be mediated by direct inhibition of MSNs rather than by indirect regulation of DA-dependent MSN excitability because silencing PV+ interneurons had no effect on AMPH-induced DA release (Figure 3). We did find lower basal levels of DA in the TeLC-expressing mice, which we interpret as likely to arise as a consequence of the failure of these mice to sensitize, given that elevated DA levels are detected in the NAc following sensitization (Pierce and Kalivas, 1997). Although it is feasible that chronic PV+ neuron silencing in the NAc could reduce basal but not AMPH-induced DA release and induce chronic MSN adaptations that underlie the sensitization failure, a cellular mechanism for this regulation would be complex and is not known. Notably in addition to the $\mathrm{PV}+$ population of GABAergic interneurons, somatostatin-positive, lowthreshold spiking interneurons are also found in the NAc, where they also make strong inhibitory synapses onto MSNs (Tepper and Bolam, 2004); however, their function in locomotor sensitization remains to be determined.

In addition to blocking locomotor sensitization we found that silencing neurotransmission from PV+ GABAergic interneurons of the NAc also impaired AMPH-induced CPP. A similar positive regulatory role in psychostimulantinduced CPP has also been ascribed to the choline acetyltransferase (ChAT)+ interneuron population of the NAc (Witten et al, 2010). Although these neurons use ACh as a neurotransmitter, optogenetic stimulation of ChAT+ neurons has been found to enhance GABAergic IPSCs recorded from MSNs, suggesting that the net effect of ChAT + interneuron firing in striatal circuits is MSN inhibition. In vivo optogenetic inhibition of ChAT+ interneurons was associated with increased MSN firing, and when ChAT+ neurons were silenced during the conditioning phase of a cocaine CPP procedure, mice failed to show cocaineconditioned chamber preference. Taken together, both of these studies suggest that the suppression of NAc output may be required for reward-induced conditioning. Notably our data also show that impaired inhibition in the NAc is not associated with a general hedonic deficit as determined by sucrose preference, suggesting that the inhibition of MSN firing is more important for pairing the reward with a location or an action rather than encoding the reward itself.

\section{AMPH-Induced Plasticity of PV+ Interneurons?}

The data presented here raise the question of whether and how AMPH-induced changes in the function of $\mathrm{PV}+$ interneurons contribute to the development of locomotor sensitization and CPP. Chronic cocaine exposure has been shown to drive an increase in intrinsic excitability of FSIs in the NAc, which could feed forward to enhance MSN inhibition (Winters et al, 2012). PV+ interneurons of the $\mathrm{NAc}$ are subject to AMPH-induced changes in expression of Fos and regulation of the methyl-DNA-binding protein $\mathrm{MeCP} 2$, suggesting that they could experience long-lasting changes in gene expression (Deng et al, 2010, 2014). One stimulus-regulated gene product that has the potential to have direct effects on $\mathrm{PV}+$ interneuron function as well as indirect effects on local microcircuits is PV itself (Donato et al, 2013). FSIs from Pvalb knockout mice display increased excitability compared with wild-type mice and they show altered frequency-dependent short-term plasticity at FSIMSN synapses (Orduz et al, 2013). These data suggest a model in which stimulus-induced molecular adaptations of local striatal PV+ interneurons could impact striatally guided behaviors by broadly modulating the extent and/or timing of MSN population responses. Future studies that identify AMPH-induced programs of gene regulation in $\mathrm{PV}+$ interneurons will expand our understanding of this plasticity mechanism.

\section{FUNDING AND DISCLOSURE}

This work was supported by NIH grant R01DA033610 (to AEW). The authors declare no conflict of interest.

\section{ACKNOWLEDGMENTS}

We thank Dr. Ramona Rodriguiz of the Duke University Mouse Behavioral and Neuroendocrine Analysis Core Facility for assistance with the behavioral studies and the statistical analyses.

\section{REFERENCES}

Badiani A, Oates MM, Day HE, Watson SJ, Akil H, Robinson TE (1999). Environmental modulation of amphetamine-induced c-fos expression in D1 versus D2 striatal neurons. Behav Brain Res 103: 203-209.

Bracci E, Centonze D, Bernardi G, Calabresi P (2002). Dopamine excites fast-spiking interneurons in the striatum. J Neurophysiol 87: 2190-2194.

Deng JV, Rodriguiz RM, Hutchinson AN, Kim I-H, Wetsel WC, West AE (2010). MeCP2 in the nucleus accumbens contributes to neural and behavioral responses to psychostimulants. Nat Neurosci 13: 1128-1136.

Deng JV, Wan Y, Wang X, Cohen S, Wetsel WC, Greenberg ME et al (2014). MeCP2 phosphorylation limits psychostimulantinduced behavioral and neuronal plasticity. I Neurosci 34: 4519-4527.

Donato F, Rompani SB, Caroni P (2013). Parvalbumin-expressing basket-cell network plasticity induced by experience regulates adult learning. Nature 504: 272-276.

Dong Y, Green T, Saal D, Marie H, Neve R, Nestler EJ et al (2006). CREB modulates excitability of nucleus accumbens neurons. Nat Neurosci 9: 475-477.

Franklin K, Paxinos G (2007). The Mouse Brain in Stereotaxic Coordinates, 3rd edn. Academic Press: San Diego.

Gangarossa G, Espallergues J, de Kerchove d'Exaerde A, El Mestikawy S, Gerfen CR, Herve D et al (2013). Distribution and compartmental organization of GABAergic medium-sized spiny neurons in the mouse nucleus accumbens. Front Neural Circuits 7: 22 . 
Gerfen CR, Surmeier DJ (2011). Modulation of striatal projection systems by dopamine. Annu Rev Neurosci 34: 441-466.

Gittis AH, Hang GB, LaDow ES, Shoenfeld LR, Atallah BV, Finkbeiner S et al (2011). Rapid target-specific remodeling of fastspiking inhibitory circuits after loss of dopamine. Neuron 71: 858-868.

Gittis AH, Nelson AB, Thwin MT, Palop JJ, Kreitzer AC (2010). Distinct roles of GABAergic interneurons in the regulation of striatal output pathways. J Neurosci 30: 2223-2234.

Graybiel AM, Moratalla R, Robertson HA (1990). Amphetamine and cocaine induce drug-specific activation of the $c$-fos gene in striosome-matrix compartments and limbic subdivisions of the striatum. Proc Natl Acad Sci USA 87: 6912-6916.

Guzman JN, Hernandez A, Galarraga E, Tapia D, Laville A, Vergara $\mathrm{R}$ et al (2003). Dopaminergic modulation of axon collaterals interconnecting spiny neurons of the rat striatum. J Neurosci 23: 8931-8940.

Haggkvist J, Lindholm S, Franck J (2009). The effect of naltrexone on amphetamine-induced conditioned place preference and locomotor behaviour in the rat. Addict Biol 14: 260-269.

Hu XT, Basu S, White FJ (2004). Repeated cocaine administration suppresses HVA-Ca2+ potentials and enhances activity of $\mathrm{K}+$ channels in rat nucleus accumbens neurons. J Neurophysiol 92: 1597-1607.

Kauer JA, Malenka RC (2007). Synaptic plasticity and addiction. Nat Rev Neurosci 8: 844-858.

Kawaguchi Y, Wilson CJ, Augood SJ, Emson PC (1995). Striatal interneurones: chemical, physiological and morphological characterization. Trends Neurosci 18: 527-535.

Kita H, Kosaka T, Heizmann CW (1990). Parvalbuminimmunoreactive neurons in the rat neostriatum: a light and electron microscopic study. Brain Res 536: 1-15.

Koos T, Tepper JM (1999). Inhibitory control of neostriatal projection neurons by GABAergic interneurons. Nat Neurosci 2: 467-472.

Kourrich S, Hayashi T, Chuang JY, Tsai SY, Su TP, Bonci A (2013). Dynamic interaction between Sigma-1 receptor and Kv1.2 shapes neuronal and behavioral responses to cocaine. Cell 152: 236-247.

Kourrich S, Thomas MJ (2009). Similar neurons, opposite adaptations: psychostimulant experience differentially alters firing properties in accumbens core versus shell. J Neurosci 29: 12275-12283.

Kreitzer AC (2009). Physiology and pharmacology of striatal neurons. Annu Rev Neurosci 32: 127-147.

Madisen L, Zwingman TA, Sunkin SM, Oh SW, Zariwala HA, Gu H et al (2009). A robust and high-throughput Cre reporting and characterization system for the whole mouse brain. Nat Neurosci 13: $133-140$

Mallet N, Le Moine C, Charpier S, Gonon F (2005). Feedforward inhibition of projection neurons by fast-spiking GABA interneurons in the rat striatum in vivo. J Neurosci 25: 3857-3869.

Mathews IZ, Morrissey MD, McCormick CM (2010). Individual differences in activity predict locomotor activity and conditioned place preference to amphetamine in both adolescent and adult rats. Pharmacol Biochem Behav 95: 63-71.

Mathur BN, Tanahira C, Tamamaki N, Lovinger DM (2013). Voltage drives diverse endocannabinoid signals to mediate striatal microcircuit-specific plasticity. Nat Neurosci 16: 1275-1283.

Milesi-Halle A, McMillan DE, Laurenzana EM, Byrnes-Blake KA, Owens SM (2007). Sex differences in (+)-amphetamine- and (+)-methamphetamine-induced behavioral response in male and female Sprague-Dawley rats. Pharmacol Biochem Behav 86: 140-149.

Murray AJ, Sauer JF, Riedel G, McClure C, Ansel L, Cheyne L et al (2011). Parvalbumin-positive CA1 interneurons are required for spatial working but not for reference memory. Nat Neurosci 14: 297-299.

Orduz D, Bischop DP, Schwaller B, Schiffmann SN, Gall D (2013). Parvalbumin tunes spike-timing and efferent short-term plasticity in striatal fast spiking interneurons. J Physiol 591: 3215-3232.

Peris J, Decambre N, Coleman-Hardee ML, Simpkins JW (1991). Estradiol enhances behavioral sensitization to cocaine and amphetamine-stimulated striatal $[3 \mathrm{H}]$ dopamine release. Brain Res 566: 255-264.

Pierce RC, Kalivas PW (1997). A circuitry model of the expression of behavioral sensitization to amphetamine-like psychostimulants. Brain Res Brain Res Rev 25: 192-216.

Pogorelov VM, Rodriguiz RM, Insco ML, Caron MG, Wetsel WC (2005). Novelty seeking and stereotypic activation of behavior in mice with disruption of the Dat1 gene. Neuropsychopharmacology 30: $1818-1831$.

Robison AJ, Nestler EJ (2011). Transcriptional and epigenetic mechanisms of addiction. Nat Rev Neurosci 12: 623-637.

Schiavo G, Benfenati F, Poulain B, Rossetto O, Polverino de Laureto P, DasGupta BR et al (1992). Tetanus and botulinum-B neurotoxins block neurotransmitter release by proteolytic cleavage of synaptobrevin. Nature 359: 832-835.

Tepper JM, Bolam JP (2004). Functional diversity and specificity of neostriatal interneurons. Curr Opin Neurobiol 14: 685-692.

Tepper JM, Tecuapetla F, Koos T, Ibanez-Sandoval O (2010). Heterogeneity and diversity of striatal GABAergic interneurons. Front Neuroanat 4: 150.

Ting JT, Daigle TL, Chen Q, Feng G (2014). Acute brain slice methods for adult and aging animals: application of targeted patch clamp analysis and optogenetics. Methods Mol Biol 1183: 221-242.

Todtenkopf MS, Stellar JR, Williams EA, Zahm DS (2004). Differential distribution of parvalbumin immunoreactive neurons in the striatum of cocaine sensitized rats. Neuroscience 127: 35-42.

Wan Y, Feng G, Calakos N (2011). Sapap3 deletion causes mGluR5dependent silencing of AMPAR synapses. Journal of Neuroscience 31: 16685-16691.

Wiltschko AB, Pettibone JR, Berke JD (2010). Opposite effects of stimulant and antipsychotic drugs on striatal fast-spiking interneurons. Neuropsychopharmacology 35: 1261-1270.

Winters BD, Kruger JM, Huang X, Gallaher ZR, Ishikawa M, Czaja $\mathrm{K}$ et al (2012). Cannabinoid receptor 1-expressing neurons in the nucleus accumbens. Proc Natl Acad Sci USA 109: E2717-E2725.

Witten IB, Lin SC, Brodsky M, Prakash R, Diester I, Anikeeva P et al (2010). Cholinergic interneurons control local circuit activity and cocaine conditioning. Science 330: 1677-1681.

Wolf ME (2010). The Bermuda Triangle of cocaine-induced neuroadaptations. Trends Neurosci 33: 391-398.

Yamamoto M, Wada N, Kitabatake Y, Watanabe D, Anzai M, Yokoyama $\mathrm{M}$ et al (2003). Reversible suppression of glutamatergic neurotransmission of cerebellar granule cells in vivo by genetically manipulated expression of tetanus neurotoxin light chain. J Neurosci 23: 6759-6767.

Supplementary Information accompanies the paper on the Neuropsychopharmacology website (http://www.nature.com/npp) 